\title{
Synthesis of 2-Cyclopentenones by Gold(I)-Catalyzed Rautenstrauch Rearrangement
}

\author{
Xiaodong Shi, David J. Gorin, and F. Dean Toste* \\ Center for New Directions in Organic Synthesis, Department of Chemistry, University of California, \\ Berkeley, California 94720 \\ Received March 17, 2005; E-mail: fdtoste@uclink.berkeley.edu
}

The importance of cyclopentenones as building blocks for organic synthesis continues to inspire the development of general methods for their stereoselective preparation. ${ }^{1-3}$ In 1984, Rautenstrauch reported that palladium(II) complexes catalyzed the isomerization of 1-ethynyl-2-propenyl acetates (1) to cyclopentenones (eq 1). ${ }^{4}$ This reaction and related rearrangements ${ }^{5}$ are proposed to proceed through a metal carbene intermediate, such as $\mathbf{2}$, arising from a 1,2-acetate migration. While the Rautenstrauch rearrangement provided an efficient route to cyclopentenones, it was limited to the preparation of achiral cyclopentenones substituted at the 2 and 3 positions (eq 1). On the basis of recent examples of gold(I)catalyzed cyclizations of enynes, ${ }^{6}$ we hypothesized that these catalysts might afford an increase in the scope of this reaction and allow the preparation of chiral cyclopentenones.

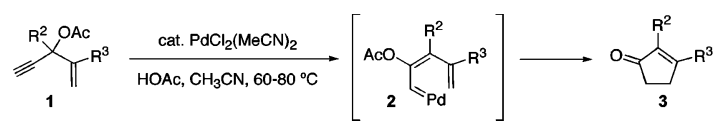

In light of our previous success employing $\mathrm{Ph}_{3} \mathrm{PAuOTf}$ in methylene chloride for carbon-carbon bond formation, ${ }^{6 b, 7}$ we chose this catalyst system in preliminary studies of the rearrangement (eq 2). To develop catalysts that would permit the synthesis of chiral cyclopentenones, we initiated our investigation with a substrate (4) containing a trisubstituted olefin. We were pleased to find that rearrangement of $\mathbf{4}$, catalyzed by $5 \mathrm{~mol} \% \mathrm{Ph}_{3} \mathrm{PAuOTf}$ in methylene chloride, did afford desired cyclopentenone 5, however, in only $30 \%$ yield. Examination of the effect of solvent on the reaction revealed that acetonitrile produced the desired adduct with a marked improvement in yield. The yield was further improved by changing the ester from acetate to pivaloate. ${ }^{8}$

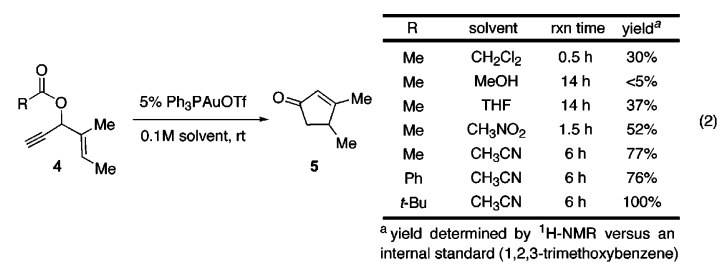

With optimized reaction conditions in hand, we set out to define the scope of the cyclopentenone synthesis. The reaction is highly tolerant of substitution at the acetylenic position of the 1-ethynyl2-propenyl pivaloates (Table 1). In addition to unsubstituted alkynes, the gold(I)-catalyzed reaction proceeded smoothly with substrates containing aryl- (entry 2), alkyl- (entry 3), and vinyl-substituted alkynes (entry 4). Cyclization of the latter produced exo-methylene cyclopentenone $\mathbf{1 3}$ after isomerization of the iso-propenyl group into conjugation with the ketone. The reaction also showed excellent scope with respect to substitution on the olefin. Specifically, 1,1disubstituted (entries 1-4), 1,2-disubstituted (entry 5), and cyclic (entries 6 and 7) alkenes participated in the cyclization. Rearrangement of styrenyl substrates 14 and 18 afforded 3-phenylcyclopen-
Table 1. Au(I)-Catalyzed Cyclopentenone Synthesis

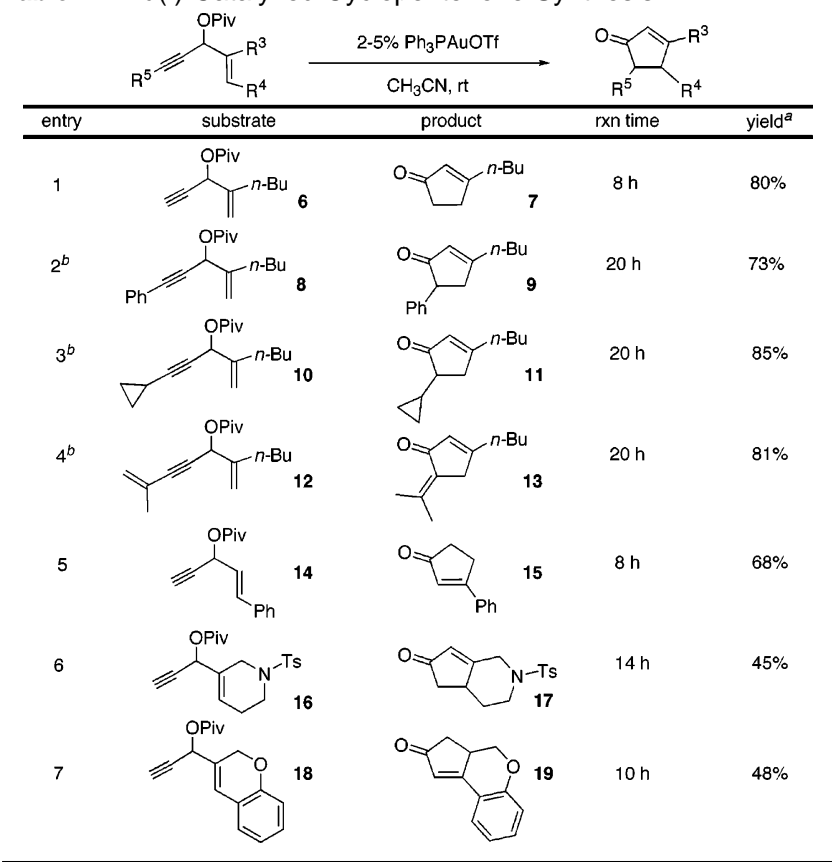

${ }^{a}$ Isolated yield after column chromatography. ${ }^{b}$ With $5 \mathrm{~mol} \% \mathrm{PPh}_{3} \mathrm{AuOTf}$ employed.

tenones $\mathbf{1 5}$ and $\mathbf{1 9}$ as a result of olefin isomerization into conjugation with the aryl group.

A 1:1 diastereomeric mixture of 20, derived from $(S)$-(-)-perillaldehyde, underwent $\mathrm{Au}$-catalyzed isomerization to produce bicyclic enone $\mathbf{2 1}$ as a 1:1 mixture of diastereomers (eq 3). We envisioned two scenarios to account for this diastereoselectivity: the stereochemistry of the starting ester is lost in generating a carbene-like intermediate (such as $\mathbf{2}$ ) that undergoes subsequent cyclization with no selectivity, or the stereochemistry of the starting pivaloate influences that of the product. To probe this question, diastereoenriched $\mathbf{2 0}$ was subjected to the reaction condition furnishing $\mathbf{2 1}$ as a 7:1 mixture of diastereomers, strongly suggesting that stereochemistry of the starting ester influences that of the product cyclopentenone.

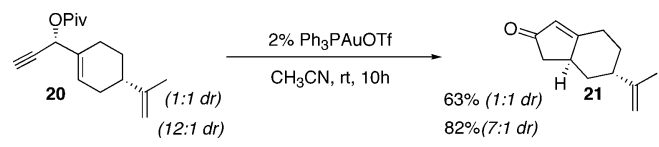

On the basis of this observation, a series of enantioenriched propargyl pivaloates ${ }^{9}$ were prepared in order to examine the chirality transfer in the cyclization. Rearrangement of enantioenriched $\mathbf{2 4}$ ( $93 \%$ ee) under the standard conditions $\left(\mathrm{Ph}_{3} \mathrm{PAuOTf}, \mathrm{CH}_{3} \mathrm{CN}\right.$, rt) cleanly afforded $\mathbf{2 5}$, however, with only $68 \%$ ee. Switching the counterion from triflate to hexafluoroantimonate and lowering the temperature to $-20{ }^{\circ} \mathrm{C}$ allowed for isolation of $\mathbf{2 5}$ in $86 \%$ yield 
Table 2. Enantioselective Cyclopentenone Synthesis

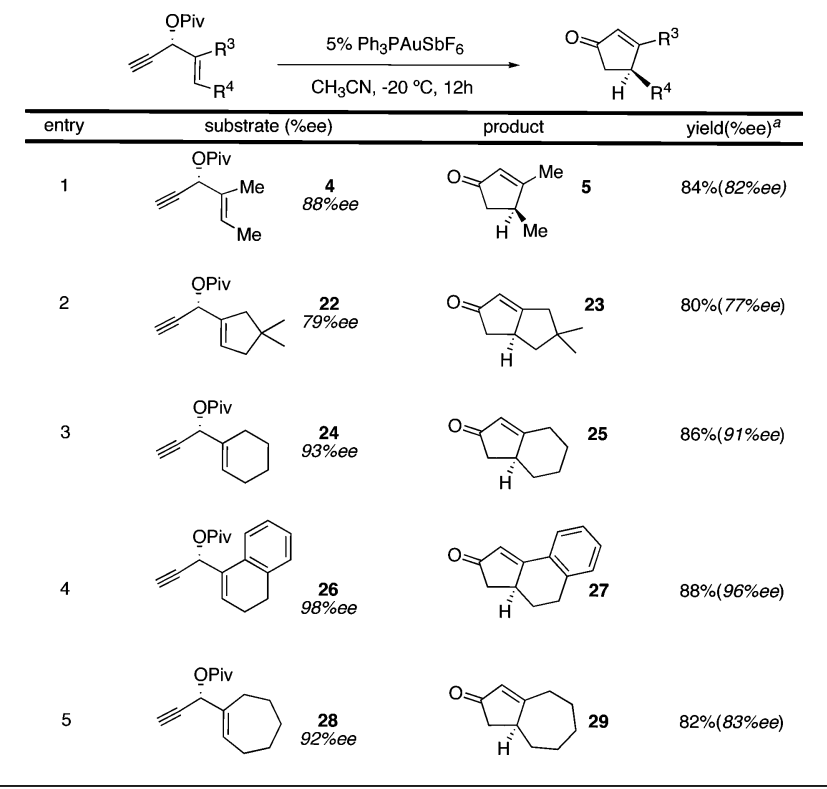

${ }^{a}$ Isolated yield after column chromatography; \% ee determined using chiral HPLC or GC (see Supporting Information for details).

Scheme 1. Proposed Mechanism for the $A u(I)$-Catalyzed Cyclopentenone Synthesis

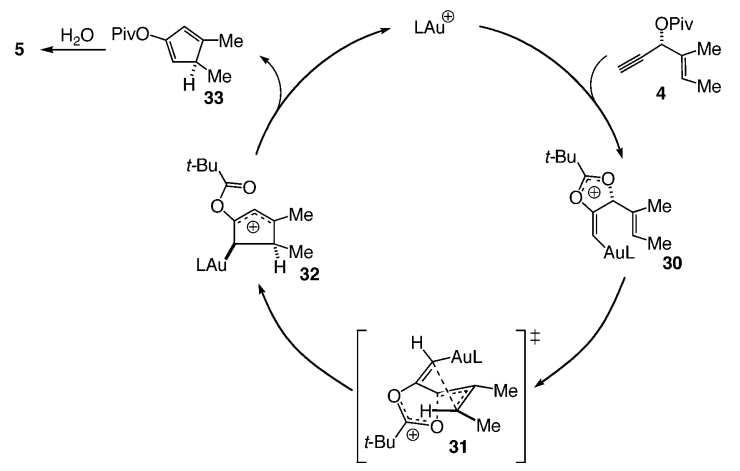

and with $91 \%$ ee (Table 2, entry 3). Under these conditions, Au(I)catalyzed rearrangement of enantioenriched propargyl pivaloates delivered cyclopentenones with excellent chirality transfer (Table 2). ${ }^{10}$

A mechanistic hypothesis that accounts for the stereochemical course of the $\mathrm{Au}(\mathrm{I})$-catalyzed rearrangement is shown in Scheme 1. Intramolecular 1,2-addition of the ester onto the alkyne, induced by coordination of the alkyne to a cationic gold(I) complex, affords vinyl gold species 30. The stereoselectivity of the gold(I)-catalyzed cyclization can be accounted for by an intramolecular cyclization that proceeds through a transition state (31) in which the leaving group occupies a position orthogonal to the plane of the olefin. ${ }^{11}$ This cyclization produces cationic intermediate 32, which upon elimination of cationic gold(I), affords diene 33. ${ }^{12}$ Finally, cyclopentadiene $\mathbf{3 3}$ is hydrolyzed to cyclopentenone $\mathbf{5}$.

In conclusion, we have developed a $\mathrm{Au}(\mathrm{I})$ catalyst for the rearrangement of 1-ethynyl-2-propenyl pivaloates to cyclopentenones. The gold(I)-catalyzed reactions are tolerant of substitution at the acetylenic and olefinic positions (except for Z-olefins), thus providing access to a wide range of cyclopentenones under exceptionally mild conditions. Additionally, enantioenriched cyclopentenones can be prepared by the gold(I)-catalyzed cyclization of enantioenriched propargyl alcohols. The high degree of chirality transfer in these rearrangements suggests that, in this case, a mechanism involving
$\mathrm{C}-\mathrm{C}$ bond formation prior to scission of the stereogenic $\mathrm{C}-\mathrm{O}$ bond is operative. Efforts aimed at utilizing $\mathrm{Au}(\mathrm{I})$ complexes as catalysts for other rearrangements are ongoing in our laboratories.

Acknowledgment. We gratefully acknowledge the University of California, Berkeley, Boehringer Ingelheim, and Merck Research Laboratories for financial support. The Center for New Directions in Organic Synthesis is supported by Bristol-Myers Squibb as a Sponsoring Member, and Novartis Pharma as a Supporting Member.

Supporting Information Available: Experimental procedures and compound characterization data (PDF). This material is available free of charge on the Internet at http://pubs.acs.org.

\section{References}

(1) Asymmetric Pauson-Khand-type reactions catalyzed by Co: (a) Hiroi, K.; Watanabe, T.; Kawagishi, R.; Abe, I. Tetrahedron: Asymmetry 2000 11, 797-808. (b) Sturla, S. J.; Buchwald, S. L. J. Org. Chem. 2002, 67 3398-3403. Ti: (c) Hicks, F. A.; Buchwald, S. L. J. Am. Chem. Soc 1999, 121, 7026-7033. Rh: (d) Jeong, N.; Sung, B. K.; Choi, Y. K. J. Am. Chem. Soc. 2000, 122, 6771-6772. (e) Shibata, T.; Toshida, N.; Takagi, K. J. Org. Chem. 2002, 67, 7446-7450. Ir: (f) Shibata, T. Takagi, K. J. Am. Chem. Soc. 2000, 122, 9852-9853. For examples of asymmetric Pauson-Khand reaction using chiral auxiliaries, see: (g) Rivero, M. R.; de la Rosa, J. C.; Carretero, J. C. J. Am. Chem. Soc. 2003, 125,14992 and references therein.

(2) For catalytic asymmetric Nazarov cyclizations, see: (a) Liang, G.; Trauner, D. J. Am. Chem. Soc. 2004, 126, 9544. (b) Aggarwal, V. K.; Belfield, A. J. Org. Lett. 2003, 5, 5075. For asymmetric Nazarov cyclizations of chiral allenes, see: (c) Tius, M. A. Acc. Chem. Res. 2003, 36, 284.

(3) For alternative asymmetric syntheses of cyclopentenones, see: (a) Tanaka, K.; Fu, G. C. J. Am. Chem. Soc. 2002, 124, 10296. (b) Barluenga, J.; Tomás, M.; Ballesteros, A.; Santamaría, J.; Brillet, C.; Garía-Granda, S. Piñera-Nicolás, A.; Vázquez, J. T. J. Am. Chem. Soc. 1999, 121, 4516.

(4) Rautenstrauch, V. J. Org. Chem. 1984, 49, 950.

(5) (a) Mainetti, E.; Mouriés, V.; Fensterbank, L.; Malacria, M.; MarcoContelles, J. Angew. Chem., Int. Ed. 2002, 41, 2132. (b) Miki, K.; Ohe, K.; Uemura, S. J. Org. Chem. 2003, 68, 8505. (c) Nevado, C.: Cárdenas, D. J.; Echavarren, A. M. Chem. - Eur. J. 2003, 9, 2627. (d) Mamane, V.; Gress, T.; Krause, H.; Fürstner, A. J. Am. Chem. Soc. 2004, 126, 8654 (e) Harrak, Y.; Blasykowski, C.; Fensterbank, L.; Malacria, M. J. Am. Chem. Soc. 2004, 126, 8656

(6) (a) Neito-Oberhuber, C.; Muñoz, M. P.; Buñuel, E.; Nevado, C.; Cárdenas, D. J.; Echavarren, A. M. Angew. Chem., Int. Ed. 2004, 43, 2402. (b) Luzung, M. R.; Markham, J. P.; Toste, F. D. J. Am. Chem. Soc. 2004 126, 10858. (c) Zuang, L.; Kozmin, S. A. J. Am. Chem. Soc. 2004, 126 , 11806. (d) Sherry, B. D.; Toste, F. D. J. Am. Chem. Soc. 2004, 126, 15978 (e) For an excellent review of homogeneous gold-catalyzed reactions, see: Hashmi, A. S. K. Gold Bull. 2004, 37, 51.

(7) (a) Kennedy-Smith, J. J.; Staben, S. T.; Toste, F. D. J. Am. Chem. Soc. 2004, 126, 4526. (b) Staben, S. T.; Kennedy-Smith, J. J.; Toste, F. D. Angew. Chem., Int. Ed. 2004, 43, 5350.

(8) Under these conditions (5\% catalysts, $0.1 \mathrm{M}$ acetonitrile, rt, $14 \mathrm{~h}$ ), other metal complexes produced the following results: AgOTf (100\% recovered 4, $0 \%$ 5); $\mathrm{AuCl}_{3}\left(0 \%\right.$ 4, $50 \%$ 5); $\mathrm{PdCl}_{2}(\mathrm{MeCN})_{2}\left(62 \%\right.$ 4, $0 \%$ 5); $\mathrm{PtCl}_{2}$ $(100 \% \mathbf{4}, 0 \% \mathbf{5}), \mathrm{CuBr}(100 \% \mathbf{4}, 0 \% \mathbf{5})$.

(9) Enantioenriched propargyl alcohols were prepared by reduction of the corresponding ketone with $R$-Alpine-Borane and the absolute stereochemistry assigned according to Midland, M. M.; McDowell, D. C.; Hatch, R. L.; Tramontano, A. J. Am. Chem. Soc. 1980, 102, 867.

(10) The absolute stereochemistry of cyclopentenone $\mathbf{2 3}\left([\alpha]_{D}=-174(c 1.25\right.$ $\left.\mathrm{CHCl}_{3}\right)$ ) was assigned by comparison of optical rotation to that reported

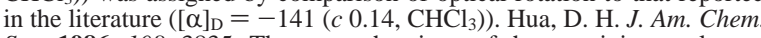
Soc. 1986, 108, 3835. The stereochemistry of the remaining cyclopentenones was assigned by analogy.

(11) This transition state also accounts for the observation that rearrangement of a 1:2 mixture of $Z: E$ olefin isomers (34) returned the $Z$-isomer unreacted. Cyclization of the $Z$-isomer would require that the olefin substituent come into close proximity to the vinyl gold.

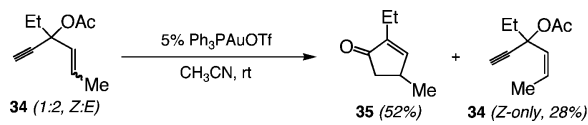

(12) In accord with this proposed intermediate, diene $\mathbf{3 7}$ was isolated from cycloisomerization of $\mathbf{3 6}$.

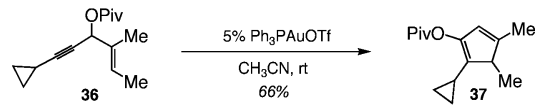

JA051689G 